\title{
Uma política para o continente - reinterpretando a Doutrina Monroe ${ }^{1}$
}

\author{
A policy for the continent-reinterpreting the Monroe Doctrine
}

http://dx.doi.org/10.1590/0034-7329201400307

CARLOS GUSTAVO POGGIO TEIXEIRA*

Rev. Bras. Polít. Int. 57 (2): 115-132 [2014]

Em 18 de novembro de 2013, o Secretário de Estado dos Estados Unidos, John Kerry, fez um pouco notado discurso na Organização dos Estados Americanos (OEA) em que afirmou categoricamente que "a era da Doutrina Monroe terminou" (Keck 2013). Tal assertiva carrega consigo um peso simbólico bastante significativo do ponto de vista das relaçôes internacionais entre Estados Unidos e seus vizinhos ao sul e traz à tona a oportunidade de um reexame desse que é um dos mais longevos princípios de política externa dos Estados Unidos.

A frase que ficou conhecida na história como resumindo o espírito da chamada Doutrina Monroe - "A América para os Americanos" - ajudou a consolidar a percepção de que a referida política tinha como alvo a totalidade do continente americano. Ainda que o próprio presidente Monroe jamais tenha proferido tal frase durante o seu discurso anual ao Congresso dos Estados Unidos em 1823, considerado o marco da Doutrina Monroe, o mandatário norte-americano foi muito claro ao declarar em um determinado momento do discurso que "devemos considerar qualquer tentativa da parte deles [europeus] de estender seu sistema para qualquer parte desse hemisfério como um perigo para a nossa paz e segurança." Em 1823, é forçoso lembrar, duas circunstâncias tornavam a mensagem de Monroe particularmente interessante: o fato de os países ao sul dos Estados Unidos terem recentemente completado seu processo de independência política em relação à Europa por um lado, e as relativamente modestas forças militares norte-americanas de então por outro. A conjunção desses fatores tornava a mensagem de Monroe ao

1 Todas as traduções de citações feitas nesse artigo são de responsabilidade do autor. Esse artigo é baseado em livro do mesmo autor: TEIXEIRA, Carlos Gustavo Poggio (2012), Brazil, the United States, and the South American Subsystem. Lanham, Lexington.

* Departamento de Política da Faculdade de Ciências Sociais da Pontifícia Universidade Católica de São Paulo, São Paulo, SP, Brasil (cgpteixeira@gmail.com). 
mesmo tempo pertinente, visto que havia um sentido em consolidar a separação em relação ao "sistema" Europeu a fim de evitar futuras tentativas de colonização, e impraticável àquela altura, visto que os Estados Unidos não dispunham ainda dos meios para sua aplicação. Não é de se espantar que o recado de Monroe fosse pouco notado pelas potências europeias.

De fato, aquilo que conhecemos como Doutrina Monroe não nasceu em 2 de dezembro 1823, dia da mensagem de Monroe ao Congresso. Só podemos falar em uma doutrina a partir do momento em que os princípios enunciados naquela data foram interpretados, articulados e usados como elementos componentes da formulação de política externa dos Estados Unidos pelos governos subsequentes. Apenas o exame desse processo histórico permite ao analista fazer generalizações sobre o real escopo da Doutrina Monroe. Repetidas análises, particularmente na academia norte-americana, tem reforçado a visão da Doutrina Monroe como sendo uma política de escopo claramente continental, "a política de abrangência hemisférica dos Estados Unidos" (Black 1977, 8, grifo meu) o que implicaria de forma inequívoca que "a totalidade do continente Americano [tinha sido] diretamente designada como esfera de interesse dos Estados Unidos" (Bloom 1990, 92, grifo meu). Tal interpretação permanece em voga em estudos mais recentes, com autores afirmando que "através da Doutrina Monroe [os Estados Unidos] reivindicaram a totalidade do hemisfério ocidental como sua província" (Heiss 2002, 519, grifo meu) e, portanto o "direito de intervir em todo o hemisfério" (Lens 2003, 98). Em um livro publicado em 2010, o autor afirma categoricamente que a ideia central da Doutrina Monroe era a conclusão de que os Estados Unidos deveriam "controlar todo o hemisfério ocidental e, consequentemente, os novos Estados da América Latina” para garantir sua segurança (Sexton 2010, 10, grifo meu). Da mesma forma, o chamado Corolário Roosevelt, a mais famosa derivação da Doutrina Monroe, também tem recebido o mesmo tratamento analítico. De acordo com a interpretação em voga, o Corolário Roosevelt da Doutrina Monroe significava que os Estados Unidos reivindicavam o direito de "intervir em conflitos entre países americanos na América Central e do Sul com a finalidade de manter a estabilidade econômica e a democracia" (Murphy 2005, 6), e que os Estados Unidos tomariam "medidas corretivas sempre que países Latino-Americanos não honrassem suas dívidas" (Gilderhus 2006, 10), agindo assim como o "policial exclusivo do hemisfério ocidental" (Ricard 2006, 17).

O presente artigo pretende reinterpretar essa natureza "hemisférica" ou "continental" da Doutrina Monroe e suas derivações a partir de uma perspectiva histórica que considere tanto o elemento discursivo quanto o processo de interação entre os países do continente americano a fim de demonstrar que tal política não era de fato "hemisférica", mas sim "caribenha". Tal distinção é importante na medida em que permite compreender que na América do Sul a doutrina - tanto na teoria quanto na prática - adquiriu um caráter completamente distinto do restante da América Latina. Como o objetivo é mapear a visão da doutrina a partir dos próprios 
Estados Unidos, a esmagadora maioria das fontes utilizadas é de autores daquele país. A partir da análise dessas fontes, o artigo sugere que dois fatores contribuíram para esse processo: a relativa distância geográfica da América do Sul e a relativa estabilidade dos países sul-americanos. Esses dois fatores tornaram possível o estabelecimento de um subsistema sul-americano cuja espinha dorsal era constituída por Argentina, Brasil, e Chile. Conforme será demonstrado, particularmente o Brasil considerava-se na América do Sul um garantidor da Doutrina Monroe e para esse fim buscou uma espécie de "aliança não-escrita" com os Estados Unidos com o objetivo de remover constrangimentos à atuação do Brasil no subsistema sul-americano. Ainda que os Estados Unidos não tenham dado a mesma atenção que o Brasil para tal "aliança”, a disposição brasileira era conveniente para os norte-americanos na medida em que permitia concentrar suas atençóes no Caribe. Também pretende-se apontar que o mais célebre executor da Doutrina Monroe, Theodore Roosevelt, tinha um claro entendimento do escopo geográfico ao qual a doutrina, e por conseguinte seu corolário, se aplicava. Por fim, o artigo assinala que, na medida em que o Chile via seu poder e influência na América do Sul declinar e a Argentina adotava uma política externa de caráter claramente antagônico aos Estados Unidos, a posição brasileira tornava-se ainda mais central.

\section{Estabelecendo os limites}

Tendo em vista que em nenhum momento de seu discurso em 1823 o presidente James Monroe esclareceu qual seria o escopo geográfico de sua doutrina, uma análise textual daquele pronunciamento pode levar à conclusão de que a mesma não tinha um escopo definido e que, portanto aplicava-se a toda América Latina. No entanto, para uma compreensão mais sofisticada daquela que se tornou uma das políticas centrais dos Estados Unidos para com seus vizinhos ao sul é fundamental ir além da análise textual e investigar como se deu o desenrolar histórico tanto discursivo quanto prático da Doutrina Monroe.

Para usar um linguajar construtivista, visto que em 1823 não havia ainda uma interação significativa entre os países independentes no continente americano, ao enunciar uma política de caráter aparentemente hemisférico, o presidente Monroe estabelecia um "ato social originário" que "cria expectativas em ambos os lados acerca do comportamento futuro" desencadeando assim um processo de ação e reação que criaria "significados intersubjetivos" (Wendt 1992, 405) que se consolidariam ao longo do tempo. Cumpre notar que as primeiras reações quando a mensagem de Monroe chegou aos países latino-americanos variaram de indiferença a entusiasmo. Não era de se espantar uma reação de indiferença, visto que muitos países da América Latina, cuja independência em relação aos europeus ainda era recente, estavam ainda mais ligados à Europa do que aos seus vizinhos americanos e tendiam a ver a Inglaterra, e não os Estados Unidos, como um aliado a garantir suas independências das potências continentais. Todavia, 
a possibilidade oferecida por Monroe aos países da América Latina de contar com uma segunda potência, ainda que infante, para dissuadir eventuais tentativas de recolonização, não podia ser completamente ignorada. Particularmente Argentina, Brasil, Chile, Colômbia e México demonstraram grande interesse na doutrina. Recentemente independentes e receosos das intenções de suas ex-metrópoles, esses países buscaram entender mais claramente quais meios os Estados Unidos usariam para garantir sua proteção (Perkins 1966, 160). O Império brasileiro foi o primeiro país da América do Sul a expressar sua satisfação com a mensagem de Monroe e chegou até a propor uma aliança com os Estados Unidos, no que foi seguido pelo México e pela Colômbia de Simon Bolívar. Poucos anos após Monroe proferir sua mensagem, o governo Argentino decidiu invocá-la em um conflito contra o Brasil de D. Pedro I em virtude, de acordo com o presidente Argentino, "das óbvias conexōes entre a Europa e o Brasil, mais especificamente com Portugal" (Stewart 1923, 45). A resposta norte-americana para esses casos é relevante na medida em que começava aí a se delinearem os reais contornos da política enunciada pelo presidente Monroe. Ao governo colombiano, o então Secretário de Estado e futuro presidente John Quincy Adams respondeu que "o medo da intervenção pela Santa Aliança nos países do Novo Mundo tinha praticamente desaparecido" e portanto não havia necessidade de uma aliança (Alvarez 1924, 10). No caso brasileiro, o governo do país norte-americano respondeu de forma protocolar, indicando uma aliança formal como desnecessária, e pouco depois, talvez para satisfazer os brasileiros, assinou um tratado comercial de escopo limitado. Ao governo argentino, o sucessor de Adams, Henry Clay, foi mais direto ao retrucar que o pedido de intervenção contra o Brasil era totalmente infundado e que "os Estados Unidos não se consideravam obrigados a intervir em nome da Doutrina Monroe por qualquer pedido das partes interessadas" (Ibid., 11). A fim de não deixar quaisquer dúvidas acerca da posiçāo norte-americana, Clay acrescentou que "ainda que Portugal e o Brasil permanecessem unidos, e uma guerra contra a República Argentina tivesse ocorrido por uma aliança entre ambos, isso estaria longe de representar um caso contemplado pela mensagem" (Stewart 1930, 31). Da mesma forma, ao presidente Mexicano, Clay explicou que a Doutrina Monroe não significava que os Estados Unidos haviam se comprometido legalmente a defendê-la (Alvarez 1924, 11). No entanto, diferentemente dos países sulamericanos, os mexicanos em breve aprenderiam que a doutrina também nada dizia em relação às ambições dos próprios Estados Unidos.

Evidentemente, dado que durante a maior parte do século 19 as potências europeias tinham mais capacidade do que os Estados Unidos de projetar poder na longínqua América do Sul, seria difícil imaginar que algum estadista norteamericano estaria realmente disposto a enviar tropas para territórios tão distantes de suas fronteiras a fim de garantir os preceitos implícitos na Doutrina Monroe. Já má década de 1840, o Secretário de Estado Daniel Webster viu-se na necessidade de esclarecer que a Doutrina Monroe "não nos deixou obrigados, em todos os 
momentos, a pegar em armas por qualquer indicação de sentimentos hostis pelas potências da Europa em relação à América do Sul," adicionando que "seria um caso muito diferente" se alguma potência europeia "desembarcasse tropas nas costas do Golfo do México ou começasse uma guerra em nossa vizinhança imediata" (Hart 1916, 92). Enquanto que na década de 1860 os Estados Unidos estavam tão preocupados com a presença francesa no México que já planejavam a utilização de força militar para forçar sua retirada, quando o Chile chegou a entrar em conflito com a Espanha na mesma época, o Secretário de Estado William H. Seward ofereceu tão simplesmente "o apoio moral de uma sincera, liberal, e, como achamos que deve aparecer, útil amizade" (Ibid., 153). Ou seja, na medida em que a Doutrina Monroe passava de uma mera declaração para um princípio político efetivo de política externa dos Estados Unidos, ia ficando claro que seu escopo não era tão continental como muitos vieram a crer.

Durante esse processo de ação e reação entre os Estados Unidos e governos latino-americanos, o alcance da doutrina tornava-se, portanto, gradualmente mais patente. Em sua mensagem ao Congresso em 1845, o presidente James Polk já parecia ter se convencido dos limites geográficos da Doutrina Monroe, quando ele abandonou as referências à América do Sul e declarou que

[a Doutrina Monroe] aplica-se com força cada vez maior no caso de qualquer potência europeia tente estabelecer uma nova colônia na América do Norte [...] A reafirmação desse princípio, especialmente em referência à América do Norte, é ainda hoje simplesmente a promulgação de uma política que nenhuma potência europeia deveria entreter a disposiçāoo de resistir... Deveria ser claramente anunciado ao mundo como nossa política definida que nenhuma colônia ou domínio europeu deve, com nosso consentimento, ser estabelecido em qualquer parte do continente norte-americano. (Hart, 1916, p. 153).

Essa declaração inequívoca do mandatário norte-americano deixava claro, duas décadas após a mensagem original de Monroe, que a doutrina em questão era na verdade "essencialmente uma doutrina Caribenha, afirmando o interesse vital dos Estados Unidos na tranquilidade daquilo que ele considerava ser seu mar interior" (Steel 1970, 195-196). As sucessivas alusōes ao termo "América do Norte" no lugar de referências hemisféricas continuou sendo feita com frequência durante todo o restante do século 19. Ao justificar a anexação de Santo Domingo como "uma aderência à Doutrina Monroe," o presidente Ulisses Grant declarou em 1871 que ele acreditava que "nós não deveríamos permitir nenhum governo independente nos limites da América do Norte de passar de uma condição de independência para uma de posse ou protetorado sob uma potência europeia" (Hart 1916, 114). Tal como Polk, Grant provavelmente sabia claramente porque empregava a expressão "América do Norte" e não mais simplesmente "América" ou "hemisfério ocidental". 
Possivelmente a única exceção a essa concentração "nos limites da América do Norte" tenha sido durante a disputa de fronteira entre Venezuela e a colônia britânica de Guiana na década de 1890, mas nesse caso em particular, as características pessoais do Secretário de Estado Richard Olney parecem ter desempenhado um papel central. Na verdade o governo da Venezuela estava envolvido em uma disputa fronteiriça com a Inglaterra desde a década de 1880, mas até 1895, quando Olney sucedeu Walter Gresham como Secretário de Estado, os Estados Unidos haviam sido bastante cautelosos diante dessa contenda (Young 1942, 248). Foi apenas após a posse de Olney como Secretário de Estado que os Estados Unidos decidiram adotar uma postura mais agressiva diante desse fato, forçando a Inglaterra a aceitar a arbitragem dos Estados Unidos usando como justificativa alusóes à Doutrina Monroe como sendo "o direito público reconhecido desse país"” (Hart 1916, 195). Em um aparente esforço consciente em estender o escopo geográfico tacitamente definido até então, Olney acrescentou que os estados do continente americano "ao sul, a sim como ao norte, em virtude de proximidade geográfica, de simpatia natural, de similaridade de governos constitucionais, são amigos e aliados, comerciais e políticos, dos Estados Unidos" (Ibid., 196). Obviamente, Olney sabia que não se tratava simplesmente de uma questão de amizade, mas da realidade do então crescente poderio dos Estados Unidos. Conforme Olney famosamente decretou, em um dos mais conhecidos arroubos de retórica de oficiais norte-americanos em relação à América Latina: "Hoje os Estados Unidos são praticamente soberanos nesse continente, e seu comando é lei sobre os assuntos em que tem interferência" (Ibid.). Cumpre notar que a mensagem original de Monroe fazia referência explícita a novas tentativas de colonização por parte de potência europeias e não a colônias existentes, o que significava que a interpretação de Olney da Doutrina Monroe como justificativa para intervir nesse conflito em particular era uma interpretação deveras singular, tanto que levou o governo britânico a responder, com espanto, que ainda que admitisse que "a Doutrina Monroe em si mesma faz sentido", a "disputa fronteiriça com a Venezuela não tem nada a ver com nenhuma das questôes aludidas pelo presidente Monroe. Não se trata de colonização por parte de uma potência europeia de nenhuma porção da América." A mensagem, escrita pelo primeiro-ministro britânico Lord Salisbury, concluía que a interpretação de Olney era um "estranho desenrolar" (Ibid., 200). Albert Hart, cujo livro fornece as citações acima, comenta que "nenhum Secretário de Estado anterior tinha feito uma interpretação tão ampla e abrangente" e que a versão de Olney tinha "pouca relação com a doutrina de 1823" (Ibid., 203). De fato, a disputa entre Venezuela e Guiana é aparentemente um caso isolado inserido dentro de um padrão mais geral, na medida em que foi talvez o único exemplo relevante em que a doutrina fora explicitamente invocada para justificar ações dos Estados Unidos aos sul do Panamá. O próprio Richard Olney declararia, no ano seguinte, quando a insurreição cubana começava a ocupar a mente dos líderes 
norte-americanos, de que ainda que os Estados Unidos estivessem "interessados em qualquer disputa em qualquer lugar por instituições políticas mais livres”, ele achou por bem esclarecer que "necessariamente e em especial medida em uma disputa que está recrudescendo quase à vista das nossas costas" (Ibid, 208). De fato, a questão cubana acabaria por levar os Estados Unidos a concentrarem-se na estratégica região do Caribe, retornando a um padrão de negligência em relação a seus distantes vizinhos sul-americanos. Novamente, a realidade geopolítica forçou o confinamento da doutrina aos seus limites geográficos reais.

Evidentemente, conforme ficava claro para os diferentes países latinoamericanos o verdadeiro escopo geográfico da Doutrina Monroe, as reações começaram a diferir do apoio quase unânime recebido logo após 1823. Mormente, após a expansão dos Estados Unidos para território mexicano a partir de 1848, deixava claro para mexicanos e seus vizinhos caribenhos e centro-americanos que "a Doutrina Monroe nunca fora uma garantia contra os desígnios ambiciosos dos próprios Estados Unidos” (Ibid., 72). Na medida em que uma "política de hegemonia" tornava-se "o complemento natural da Doutrina Monroe" não era de se surpreender que alguns países, o México em particular, começassem a desenvolver "uma grande aversão à Doutrina, visto que eles normalmente a viam não a partir do aspecto que tivera em 1823 mas a partir do novo aspecto que havia sido atribuído a ela" (Alvarez 1924, 19-20). Após a Guerra Mexicano-Americana de 1846, quando os Estados Unidos ampliaram grandemente seu território à custa do México, e a Guerra Hispano-Americana de 1898, quando Guam, Porto Rico e as Filipinas foram ocupados, esse novo aspecto da doutrina havia ficado bastante evidente. De forma absolutamente pouco surpreendente, ao iniciar-se o novo século, o presidente do México viu-se obrigado a declarar publicamente sua oposição à Doutrina Monroe na medida em que a mesma, de acordo com ele, "ataca a soberania e a independência do México e estabelece uma tutelagem sobre todos os países da América” (Thomas 1923, 395). O crescimento do poderio norteamericano concomitantemente com o declínio das potências europeias, ambos claramente simbolizados pela guerra de 1898, mudara completamente a visão que diversos países latino-americanos detinham da Doutrina Monroe enquanto uma garantia contra intervenção externa. A questão que passava a dominar as sucessivas conferências Pan-americanas agora era como lidar com a evidente disparidade de poder existente no continente americano entre os Estados Unidos e as nações latino-americanas e o temor que isso causava em relação à soberania dessas. Como destaca Gordon Cornell-Smith $(1966,10)$, "um sistema que foi promovido para prevenir intervençôes extracontinentais de repente passou a se preocupar com a questão da intervenção pela potência promotora do sistema”. Após a Guerra Hispano-Americana e seguidas intervenções na América Central e no Caribe durante as primeiras décadas do século 20, restaria evidente que a noção de uma política "latino-americana" homogênea era um equívoco de análise. Tendo na 
virada do século derrotado uma potência europeia decadente, e ainda vivendo em um mundo de impérios, os próprios Estados Unidos começavam a flertar com soluçōes imperiais para si. Entretanto, se de fato um "império americano" surgia, era um império com alcance que raramente ultrapassava o sul do Panamá ${ }^{2}$. Como será demonstrado a seguir, em virtude de suas distintas experiências com o poderio dos Estados Unidos, os países da América do Sul em grande medida desenvolveram visōes consideravelmente distintas daquelas que tinham os demais países da América Latina, o que pode ser claramente exemplificado pelos casos de México, por um lado, e Brasil, de outro.

\section{Consolidando os limites}

A evidente importância estratégica do Caribe para os Estados Unidos em comparação com os países mais distantes ao sul é um fator central para explicar a relativa falta de envolvimento do país norte-americano na América do Sul, mas não o único. Um outro fator - que evidentemente não é dissociado daquele - foi o desenvolvimento de um subsistema regional sul-americano em torno de um núcleo formado por Argentina, Brasil e Chile, que por sua vez era relativamente separado do subsistema norte-americano. O fato de os Estados Unidos encontrarem-se geograficamente distantes da América do Sul e, durante a maior parte do século 19, não terem ainda capacidade efetiva de projeção de poder naquela região, permitiu o desenvolvimento de um subsistema separado ao longo daquele século. Assim, quando os Estados Unidos efetivamente adquiriram capacidade de efetivamente transformar a Doutrina Monroe em uma política verdadeiramente continental e não apenas caribenha, os estadistas norte-americanos teriam que lidar com um subsistema regional já razoavelmente consolidado em termos de sua diferenciação em relação ao restante da América Latina.

Diferentemente da esmagadora maioria das ex-colônias espanholas, tanto Argentina como Chile lograram desenvolver governos relativamente estáveis após suas independências. Apesar de alguns momentos de precariedade política, especialmente no caso da Argentina, nenhum desses dois países experimentou o tipo de instabilidade generalizada que prevaleceu no México, por exemplo, onde pelo menos meia dúzia de governos diferentes alternaram-se no poder entre o reconhecimento da sua independência, em 1821, e o fim da guerra com os Estados Unidos em 1848. O caso do Brasil era bem diferente visto que, em contraste com a América espanhola, o país havia conseguido evitar a fragmentação

2 Martin Sicker conta trinta e quatro intervenções dos Estados Unidos na América Central e no Caribe entre 1890 e 1928. Sicker, M. (2002). The Geopolitics of Security in the Americas: Hemispheric Denial from Monroe to Clinton. Westport, Conn., Praeger. Por outro lado, como observa G. Pope Atkins, os Estados Unidos "nunca desembarcaram tropas no Cone Sul". Atkins, G. P. (1999). Latin America and the Caribbean in the International System. Boulder, Colo., Westview Press. 
política e, na verdade, quaisquer rupturas significativas depois de declarada sua independência de Portugal. $\mathrm{O}$ fato de o primeiro líder do Brasil independente ter sido filho do monarca português e ter reinado por nove anos e subsequentemente passado o poder ao seu filho, que por sua vez foi imperador por quase cinquenta anos ininterruptos, é ilustrativo disso. Além disso, D. Pedro II estava longe de representar o modelo do caudilho latino-americano que imperava na América espanhola, sendo um estadista liberal e erudito, que conviveu com o funcionamento de um ativo parlamento com partidos relativamente sólidos. Quando da morte de D. Pedro II, o jornal The New York Times publicou um obituário extremamente elogioso, uma deferência bastante rara de um jornal norte-americano para um monarca, e mais rara ainda em se tratando de um líder latino-americano. $\mathrm{O}$ jornal chamou o imperador brasileiro de "um dos mais iluminados monarcas do século [...] um patrono liberal das letras, artes, e ciências" adicionando ainda que "Dom Pedro fez do Brasil o mais livre que uma monarquia poderia ser" (The New York Times, 5 de dezembro de 1891). No dia seguinte, o jornal norte-americano referiuse a D. Pedro como um "filósofo genial" e, o que é realmente surpreendente tendo em vista a ideia de separação entre os sistemas de governo europeu e americano que era base da Doutrina Monroe, questionou a sabedoria da instauração de uma república no Brasil, afirmando que "é duvidoso que uma república seja tão adequada ao Brasil quanto uma monarquia" (The New York Times, 6 de dezembro de 1891). Independente da validade da análise dos jornalistas do The New York Times, tais assertivas parecem deixar claro o desenvolvimento de uma opinião pública nos Estados Unidos de caráter consideravelmente distinta daquela que já estava consolidada quando o tema era qualquer país ao norte do Panamá. Além disso, mesmo nos anos iniciais República, o Brasil desfrutaria de considerável estabilidade política, fato que pode ser ilustrado pela permanência do Barão do Rio Branco como Ministro das Relações Exteriores durante quatro diferentes governos, entre 1902 e 1910. Portanto, além de sua considerável extensão territorial, fazendo fronteira com quase todos os vizinhos sul-americanos, a relativa estabilidade política brasileira permitiu ao Brasil consolidar-se como uma potência regional na América do Sul com certa antecedência.

Dessa forma, no despertar do século 20, Argentina, Brasil e Chile representavam um grupo de países desfrutando de uma estabilidade incomum se comparados aos seus vizinhos latino-americanos. Isso permitiu o desenvolvimento de um subsistema regional logo no início da vida política daqueles Estados. Assim, devido à presença de três países geograficamente próximos e razoavelmente dotados de recursos de poder, conjugado com a distância desses em relação aos Estados Unidos, os países da América do Sul estavam na verdade muito menos preocupados com o vasto poder norte-americano do que consigo próprios. Robert Burr (1955; 1962; 1967) descreve o desenvolvimento de um sistema de política de poder sulamericano durante o século 19 como tendo originalmente sido constituído de 
duas sub-regiōes - a região do La Plata e a Andina - que posteriormente teriam se fundido em um único sistema "continental" já em meados dos anos 1860. Destarte, os estadistas sul-americanos, pelo menos desde a segunda metade do século 19, "tendiam a pensar em termos de um sistema de equilíbrio de poder de alcance continental" e referiam-se frequentemente a existência de um "equilíbrio sul-americano" (Burr 1962, 17, 29, 113). Conforme argumenta Burr, ao final do século 19, "a ideia de um equilíbrio de poder tornara-se uma parte natural da vida internacional da América do Sul” (Burr 1955, 59). De fato, a noção de que existia uma clara separação entre as Américas do Sul e do Norte já podia ser detectada nas mentes de estadistas sul-americanos desde pelo menos 1840. Por exemplo, quando problemas domésticos no México pareciam indicar que as tentativas de se organizar uma conferência entre os Estados americanos naquele ano iriam fracassar, o representante chileno sugeriu que "talvez fosse melhor que os plenipotenciários sul-americanos se encontrassem em separado [...] sem esperar pela chegada [...] de seus colegas mexicanos e centro-americanos" adicionando categoricamente que "[a]s repúblicas da América do Sul e o Império do Brasil forma um sistema compacto cujos laços com o México e a América Central são comparavelmente fracos" (Burr 1967, 62-63).

Enquanto que a relativa distância em relação aos Estados Unidos colocava os países sul-americanos fora do escopo real da Doutrina Monroe e deixava-os menos preocupados do que seus colegas mexicanos, caribenhos e centro-americanos com uma intervenção dos Estados Unidos, na mediada em que o poderio e a estabilidade de Argentina, Brasil, e Chile tornavam-se mais claros, alguns formuladores de política norte-americanos começaram a considerar novas possibilidades de aplicação da Doutrina a fim de manter a estabilidade no continente. Ou seja, os Estados Unidos se responsabilizariam diretamente pela metade norte do continente, ao passo em que incentivariam a participação de potências regionais sul-americanas nos assuntos que diziam respeito àquela parte do continente americano. Ainda que pouco explorado pela literatura, esse arranjo tornar-se-ia um fator-chave na separação entre os subsistemas regionais sul e norte-americanos em seus anos iniciais de formação. Já em meados do século 19, o presidente Ulisses Grant mostrava os embriōes dessa abordagem quando considerou a possibilidade de intervir em uma disputa ente Chile e Peru. Deixando de lado a fraseologia unilateral que caracterizava as referências ao México, América Central e Caribe, o presidente do país norte-americano mencionou a possibilidade de intervenção qualificando que os Estados Unidos "se sentiriam livres para apelar às outras repúblicas do continente em um esforço conjunto para evitar as consequências de algo que não pode ser confinado ao Chile e ao Peru" (Hart 1916, 180). Todavia, a noção de uma possível "entente" entre os Estados Unidos e potências regionais sul-americanas só seria plenamente desenvolvida por aquele que se tornaria o mais célebre rearticulador da Doutrina Monroe - Theodore Roosevelt. De fato, 
o presidente que ficou famoso por dizer que os Estados Unidos deveriam carregar "um grande porrete" para manter a ordem na sua vizinhança, é possivelmente o primeiro chefe de Estado norte-americano a considerar explicitamente as vantagens de compartilhar responsabilidades para aplicação da Doutrina Monroe na parte sul do continente.

\section{O corolário Roosevelt}

Em um capítulo de sua autobiografia intitulada "A Doutrina Monroe e o Canal do Panamá”, Theodore Roosevelt $(1913,502)$ inicia reconhecendo que a guerra com a Espanha havia deixado os Estados Unidos "com relações peculiares com as Filipinas, Cuba, Porto Rico, e com enormes interesses adicionais na América Central e no Mar do Caribe", delimitando claramente assim os limites da esfera de influência imediata dos Estados Unidos à época, tal como seus antecessores haviam feito. Algumas linhas adiante, porém, ele acrescenta:

As grandes e prósperas comunidades civilizadas como a Argentina, o Brasil, e o Chile, na metade sul da América do Sul, têm feito tantos avanços que eles não mais se colocam em posição de necessitar de qualquer tutelagem por parte dos Estados Unidos. Eles ocupam em relação a nós exatamente a posição que o Canadá ocupa. A amizade deles é uma amizade de iguais para iguais. Minha visão em sobre essas nações era de que a necessidade de afirmar a Doutrina Monroe em relação a eles é a mesma que afirmar em relação ao Canadá. (Ibid, p. 503).

Roosevelt ainda conclui que se alguma nação europeia tentasse ocupar algum desses países, os Estados Unidos iriam prover assistência, mas “a iniciativa viria da própria nação, e os Estados Unidos agiriam apenas como um amigo cuja ajuda foi solicitada". Evidentemente, como ele se apressa a destacar, a situação seria "radicalmente diferente" no caso dos "Estados na vizinhança do Mar do Caribe" (Ibid.).

O raciocínio de Roosevelt para esse - frequentemente ignorado - aspecto de seu corolário à Doutrina Monroe baseava-se em dois pilares principais. $\mathrm{O}$ primeiro é o estratégico-militar. Já em 1901, o Conselho Geral da Marinha dos Estados Unidos havia produzido um relatório afirmando que

Se o princípio da Doutrina Monroe, enquanto for política desse governo, cobre toda a América do Sul, incluindo a Patagônia e a Argentina, não é da alçada desse Conselho Geral, mas apenas o fato de que os princípios de estratégia e os defeitos de nossa posição geográfica torna impraticável manter de forma bem sucedida controle naval pelas forças armadas além da Amazònia, a não ser que as condiçōes atuais mudem radicalmente (Langley, 1985, p. 20). 
Tal visão era compartilhada pelo famoso estrategista, teórico da geopolítica e amigo de Roosevelt, Capitão Alfred Mahan, que acreditava que "as preocupações de segurança dos Estados Unidos terminam no Rio Amazonas, tornando desnecessário a aplicação da Doutrina Monroe ao sul dele" (Healy 1988, 144).

A esse pilar estratégico, Roosevelt acrescentaria um outro, de natureza política, qual seja, de capacidade estatal. Em outras palavras, os Estados Unidos deveriam intervir naqueles países que se provassem incapazes de "cumprir suas obrigaçóes para com países estrangeiros ou de assegurar seus direitos contra países estrangeiros" (Roosevelt 1913, 503). Em sua mensagem ao Congresso que deu origem ao seu famoso corolário, Roosevelt destacou que "transgressão ou impotência" seriam as causas que poderiam exigir uma intervenção dos Estados Unidos no hemisfério acrescentando que se os países da região do Caribe tivessem o mesmo "progresso na direção de uma civilização estável e justa [...] que tantas repúblicas em ambas as Américas tem demonstrado de forma constante e brilhante, todas as questôes de interferência por parte desta nação em seus assuntos terminariam" (Roosevelt e Lewis 1906, 857-858). Mais tarde, Roosevelt destacou explicitamente "Brasil, Argentina, Chile" que, afirmou, "atingiram posições de progresso tão seguro, de tal estabilidade política, poder, e prosperidade econômica, [...] é seguro dizer que não existe mais nenhuma necessidade de os Estados Unidos se preocuparem em afirmar a Doutrina Monroe para esses países" (Healy 1988, 144). Em outra ocasião, Roosevelt asseverou que não apenas não havia necessidade de os Estados Unidos serem "os defensores especiais da Doutrina [Monroe]", mas de que as potências regionais sul-americanas estariam "ainda que não totalmente consciente [...] entre os garantidores dessa Doutrina.” (Hart 1916, 322).

A noção de que os relativamente estáveis países sul-americanos poderiam eventualmente ser garantidores da Doutrina Monroe e não apenas objetos dela, levou um autor a comentar que Roosevelt via países como Argentina e Brasil "como parceiros júnior que ajudariam a fazer cumprir o Corolário" (Weidenmier e Mitchener 2004, 11). Outro autor apontou que "em uma explosão de entusiasmo", Roosevelt "teria dito ao Chile que, se Santo Domingo estivesse no Pacífico, ele chamaria o Chile para policiar a ilha" (Thomas 1923, 376). Quando Roosevelt já tinha deixado a presidência dos Estados Unidos, ele confirmou em uma carta ao seu filho a visão de que Argentina, Brasil, e Chile seriam parceiros a aplicar o seu corolário quando escreveu que

seria uma mera tolice, a mais boba das bobagens, pedir ao México, Venezuela, Honduras, Nicarágua, para garantir a Doutrina Monroe junto conosco. É eminentemente adequado pedir ao Brasil, Argentina e Chile para fazê-lo...; mas pedir isso aos outros países que eu mencionei para garanti-la seria o mesmo que pedir isso aos Apaches e aos Utes (Schoultz, 1998, p. 204). 
O que as citações acima deixam patente é que, se Theodore Roosevelt é comumente associado à busca de um "império" para os Estados Unidos, suas manifestas opiniōes de como a América do Sul encaixar-se-ia nesse esquema deve servir como um lembrete de que esse desejo imperial, que inequivocamente estava presente naquele momento, tinha, por questōes estratégicas e políticas, um alcance limitado do ponto de vista geográfico. ${ }^{3}$

Em certa medida, esse processo de reconhecimento de que na América Latina havia países em diferentes estágios de desenvolvimento e estabilidade política pode ser atribuído igualmente ao Secretário de Estado de Roosevelt, Elihu Root, o primeiro Secretário de Estado em exercício dos Estados Unidos a visitar países estrangeiros, incluindo países na América do Sul onde foi recebido de forma bastante calorosa. De maneira similar aos predecessores, como visto anteriormente, Root é citado como tendo afirmado que "na medida em que se passa ao sul e a distância em relação ao Caribe aumenta, a necessidade de se manter a Doutrina Monroe torna-se menos imediato e aparente" (Hart 1916, 237). Assim como Roosevelt, Root acreditava que isso se devia não apenas à distância geográfica, mas também ao fato de que ele entendia que alguns países-chave na América do Sul estavam em patamar mais elevado de organização política. Certa vez, Root chegou a comentar que gostaria de poder ajudar países da América Central a "seguir no caminho que Brasil, Argentina, Chile e Peru e outros países sul-americanos percorreram - deixando para trás a discórdia e o tumulto da revolução contínua e em direção a um senso público geral de justiça e determinação de manter a ordem (Schoultz 1988, 197). Para Lars Schoutz, "a contribuição específica de Elihu Root para as relações interamericanas foi desagregar a região em duas classes distintas uma sendo a turbulenta região do Caribe e a outra os países estáveis e progressivos da América do Sul e o México" (Ibid, 192). Como indicado anteriormente, outros formuladores de política externa dos Estados Unidos já faziam essa distinção, mas Root , com o apoio de Roosevelt, talvez tenha sido um dos primeiros a tentar articular isso de forma mais explícita. Tais considerações contradizem frontalmente muitas análises que se popularizaram desde a promulgação da Doutrina Monroe de que os líderes norte-americanos pareciam "estar cegos às reais condições das partes maiores e mais importantes da América Latina, como o Brasil, a Argentina, e o Chile" (Bringham 1913, 55). ${ }^{4}$ Esse tipo de interpretação tende a assumir que

3 Para uma análise recente acerca do imperialismo de Theodore Roosevelt ver Bradley, J. (2009). The Imperial Cruise: A Secret History of Empire and War. New York, NY, Little, Brown and Co, Thomas, E. (2010). The War Lovers: Roosevelt, Lodge, Hearst, and the Rush to Empire, 1898. New York, Little, Brown and Co.

4 Intitulado "The Monroe Doctrine: An Obsolete Shibboleth", o manuscrito ora citado, publicado em 1914, apresenta fortes críticas à Doutrina Monroe durante os anos de Roosevelt. É interessante notar que para fazer seu argumento o autor concentra-se principalmente em países sul-americanos com o objetivo de mostrar a inadequação da Doutrina. Em um determinado ponto, o autor chega a sugerir que uma política alternativa mais adequada seria que os Estados Unidos juntassem forças com Argentina, Brasil, e Chile a fim de "proteger as partes mais fracas da América contra qualquer agressão imaginável por parte de países europeus ou asiáticos" (p. 96), o que soa surpreendentemente similar à real abordagem de Roosevelt, tal como apresentado aqui. 
a Doutrina Monroe era uma política elaborada a fim de ser aplicada de forma homogênea em toda América Latina, quando o que pretendeu-se demonstrar até agora era que isso não correspondia à realidade.

Tão revelador quanto a abordagem de Roosevelt para a Doutrina Monroe é a postura de outro presidente norte-americano, não menos imperialista em suas relações com a América Latina: Woodrow Wilson. Tal como Roosevelt, "Wilson gostava de pensar que os Estados estáveis da América do Sul poderiam ter um papel em trazer a ordem para os Estados instáveis ao redor do Caribe" (Gilderhus 1986, 16). De fato, como apontam estudiosos do tema, Wilson considerava a Argentina, o Brasil, e o Chile como peças centrais de sua abordagem "Pan-Americana" (Gilderhus 1986; Healy 1988). Isso ficou evidente quando os Estados Unidos enfrentavam dificuldades na relação com o México em razão das instabilidades internas do país latino-americano desde a Revolução de 1910. Wilson considerou intervir no México, mas decidiu procurar a intermediação das três potências sul-americanas para, nas palavras de um membro do governo norte-americano da época, "dar um tom Pan-Americano" ao tema e adicionalmente "ganhar a simpatia duradoura do resto da América Latina" (Gilderhus 1986, 17). Mais tarde, quando a intervenção parecia iminente, o Departamento de Estado considerou alternativas para uma "ação conjunta" com os três países sul-americanos com o objetivo de "reduzir custos e afastar a má vontade" (Ibid., 54). Em 1915, o enviado norte-americano à Argentina sugeriu que se "finalmente for necessário, nos termos da Doutrina Monroe, que os Estados Unidos intervenham, eu sugeriria que convidássemos a Argentina ou Brasil, ou outro país americano para se juntar a nos" acrescentando que com essa atitude, a Doutrina Monroe iria "deixar de ser unilateral, o que é hoje seu grande defeito" (Hart 1916, 381). Ao fim e ao cabo, os esforços de mediação não tiveram muito impacto, o governo de Carranza no México acabou sendo reconhecido pelos Estados Unidos e demais países latinoamericanos em 1915, e nenhuma intervenção conjunta ocorreu, ainda que os Estados Unidos tenham ocupado a cidade portuária de Veracruz por sete meses em 1914. No entanto, fica evidente que, tal como Roosevelt, a visão da presidência de Wilson quanto ao intuito da Doutrina Monroe no continente americano partia da noção de que uma política distinta deveria prevalecer para os países da parte sul do continente americano.

\section{Conclusão}

Esse artigo pretendeu demonstrar que um exame mais minucioso das interaçôes iniciais entre os Estados independentes do continente americano após a declaração de Monroe em 1823 revela que as interpretações costumeiras de que a Doutrina Monroe foi traduzida como uma política a ser homogeneamente aplicada em toda América Latina possui sérias deficiências. Na verdade, um aspecto 
fundamental da tradução da Doutrina Monroe tanto no plano político como no retórico é o fato de que a mesma possuía dois aspectos distintos e longe de ser uma política "latino-americana" era uma política para todos os efeitos restrita à região do Caribe, com a América do Sul sendo considerada como um sistema em separado e que deveria cumprir um papel distinto. Essa diferenciação só foi possível porque os formuladores de políticas dos Estados Unidos compreenderam cedo que os países mais distantes na América do Sul poderiam ser organizados a partir de um núcleo de Estados - notadamente Argentina, Brasil, e Chile - que eram relativamente estáveis e que portanto poderiam ser invocados para manter a estabilidade no seu entorno geográfico. Quando tal distinção é descoberta, até mesmo um imperialista nato como Theodore Roosevelt revela um lado multilateral. Da mesma forma, Wilson, um dos presidentes mais intervencionistas na história da América Latina, que famosamente disse que ia ensinar aos latino-americanos "como eleger bons homens", demonstrou ter uma visão consideravelmente distinta da Doutrina Monroe quando aplicada à América do Sul.

A Doutrina Monroe adquiriu assim um caráter distinto na América do Sul em relação ao restante da América Latina em função de fatores geográficos e políticos. Quanto ao primeiro, a relativa distância que separava os países sul-americanos dos Estados Unidos dificultava a projeção de poder daquele país ao sul do Canal do Panamá, particularmente se considerarmos que durante a maior parte do século 19 as forças navais norte-americanas eram relativamente modestas. Quanto ao fator político, a presença de países relativamente estáveis e com recursos de poder na América do Sul permitiu aos Estados Unidos desenvolver uma abordagem de caráter multilateral a fim de evitar os altos custos associados a intervenções unilaterais. Assim, ao passo que a geografia tornava a aplicação da Doutrina Monroe na América do Sul difícil, a política a tornava desnecessária.

$\mathrm{O}$ fato de o Brasil ser um entusiasmado apoiador dos princípios originalmente enunciados em 1823 tornou-se cada vez mais relevante na medida em que, por um lado, o Chile decrescia em termos de poder relativo e, por outro, a Argentina adotava uma postura de caráter crescentemente antagônico em relação aos Estados Unidos. Tal postura de apoio por parte do Brasil, no entanto, estava atrelada à busca por garantir sua área de influência na América do Sul. Assim, tanto a política externa brasileira quanto a argentina enxergavam a relação com os Estados Unidos como um meio para estabelecer uma primazia na América do Sul, mas ao passo que a Argentina acreditava que a melhor forma de obter isso era mantendo distância a fim de demonstrar independência em relação ao país norte-americano e ser vista como líder dos países de língua espanhola, o Brasil adotava postura diversa, já que via a aproximação com os Estados Unidos como uma peça fundamental para suas pretensões de primazia na América do Sul. Em outras palavras, enquanto a Argentina buscava primazia pela via da distância, o Brasil perseguia o mesmo objetivo, mas pela via da aproximação com os Estados Unidos. 


\section{Referências bibliográficas}

ALVAREZ, Alejandro (1924). The Monroe Doctrine, its Importance in the International Life of the States of the New World. New York, Oxford University Press.

ATKINS, G. Pope (1999). Latin America and the Caribbean in the International System. Boulder, Colo., Westview Press.

BANDEIRA, Moniz (1997). Relações Brasil-EUA no Contexto da Globalização. São Paulo, Senac.

(2008). "O Brasil como Potência Regional e a Importância Estratégica da América do Sul na sua Política Exterior.” Revista Espaço Acadêmico(91).

BINGHAM, Hiram. (1913). The Monroe Doctrine: An Obsolete Shibboleth. New Haven, Yale university press.

BLACK, Jan Knippers. (1977). United States Penetration of Brazil. Philadelphia, University of Pennsylvania Press.

BLOOM, William. (1990). Personal Identity, National Identity, and International Relations. Cambridge England ; New York, Cambridge University Press.

BRADLEY, James. (2009). The Imperial Cruise: A Secret History of Empire and War. New York, NY, Little, Brown and Co.

BURNS, E. Bradford. (1966). The Unwritten Alliance: Rio Branco and Brazilian-American Relations. New York, Columbia University Press.

BURR, Robert N. (1955). "The Balance of Power in Nineteenth-Century South America: An Exploratory Essay.” The Hispanic American Historical Review 35(1): 37-60.

. (1962). The Stillborn Panama Congress; Power Politics and Chilean-Colombian Relations During the War of the Pacific. Berkeley,, University of California Press.

. (1967). By Reason or Force; Chile and the Balancing of Power in South America, 1830-1905. Berkeley, University of California Press.

CONNELL-SMITH, Gordon. (1966). The Inter-American System. London, New York, Royal Institute of International Affairs.

GILDERHUS, Mark T. (1986). Pan American Visions: Woodrow Wilson in the Western Hemisphere, 1913-1921. Tucson, University of Arizona Press. 36(1): 5-16.

“The Monroe Doctrine: Meanings and Implications.” Presidential Studies Quarterly

HART, Albert Bushnell. (1916). The Monroe Doctrine: An Interpretation. Boston, Little, Brown, and Company.

HEALY, David. (1988). Drive to Hegemony : The United States in the Caribbean, 1898-1917. Madison, Wis., University of Wisconsin Press.

HEISS, M. A. (2002). "The Evolution of the Imperial Idea and U.S. National Identity." Diplomatic History 26(4): 511-540.

HULL, Cordell and BERDING, A. H. T. (1948). The Memoirs of Cordell Hull. New York,, Macmillan Co. 
KECK, Zachary. “The US Renounces the Monroe Doctrine?” The Diplomat [online]. 21 de Novembro de 2013 [acessado em 23 de novembro de 2013]. Disponível em http://thediplomat. com/2013/11/the-us-renounces-the-monroe-doctrine/

LANGLEY, Lester D. (1985). The Banana Wars: United States Intervention in the Caribbean, 1898-1934. Lexington, Ky., University Press of Kentucky.

LENS, Sidney. (2003). The Forging of the American Empire: From the Revolution to Vietnam, a History of U.S. Imperialism. London; Sterling, Va., Pluto Press; Haymarket Books.

MURPHY, Gretchen. (2005). Hemispheric Imaginings: The Monroe Doctrine and Narratives of U.S. Empire. Durham, Duke University Press.

NAPOLEÃO, Aluizio. (1947). Rio Branco e as Relaçôes entre O Brasil e os Estados Unidos. Rio de Janeiro, Ministério das Relações Exteriores.

PERKINS, Dexter. (1966). The Monroe doctrine, 1867-1907. Gloucester, Mass.,, P. Smith.

RICARD, Serge. (2006). “The Roosevelt Corollary.” Presidential Studies Quarterly 36(1): $17-26$.

ROOSEVELT, Theodore. (1913). An Autobiography. New York, Charles Scribner's Sons.

ROOSEVELT, Theodore; LEWIS, A. H. (1906). A Compilation of the Messages and Speeches of Theodore Roosevelt, 1901-1905. New York, Bureau of National Literature and Art.

SCHOULTZ, Lars. (1998). Beneath the United States: A History of U.S. Policy toward Latin America. Cambridge, Mass., Harvard University Press.

SEXTON, Jay. (2010). The Monroe Doctrine: Empire and Nation in Nineteenth-Century America. New York, Hill and Wang.

SICKER, Martin. (2002). The Geopolitics of Security in the Americas : Hemispheric Denial From Monroe To Clinton. Westport, Conn., Praeger.

STEEL, Ronald. (1970). Pax Americana. New York, Viking Press.

STEWART, Watt. (1930). "Argentina and the Monroe Doctrine, 1824-1828." The Hispanic American Historical Review 10(1): 26-32.

The New York Times (1891). Brazil's Old ruler Dead. December, 5. (1891). Dom Pedro and Brazil. December, 6.

THOMAS, D. Y. (1923). One Hundred Years of the Monroe doctrine, 1823-1923. New York,, Macmillan.

THOMAS, Evan. (2010). The War Lovers: Roosevelt, Lodge, Hearst, and the Rush to Empire, 1898. New York, Little, Brown and Co.

WEIDENMIER, Marc D. and MITCHENER, K. J. (2004). Empire, Public Goods, and the Roosevelt corollary. Cambridge, Mass, National Bureau of Economic Research.

WEIS, W. Michael. (2000). Pan American Shift : Oswaldo Aranha and the Demise of the Brazilian-American Alliance. Beyond the ideal : Pan Americanism in Inter-American affairs. D. Sheinin. Westport, Conn., Greenwood Press: 133-152.

WENDT, Alexander. (1992). "Anarchy is What States Make of it: The Social Construction of Power Politics." International Organization 46(2): 391-425. 
WOODS, Randall Bennett. (1979). The Roosevelt Foreign-Policy Establishment and the "Good Neighbor" : the United States and Argentina, 1941-1945. Lawrence, Regents Press of Kansas.

YOUNG, George B. (1942). “Intervention Under the Monroe Doctrine: The Olney Corollary.” Political Science Quarterly 57(2): 247-280.

Recebido em 15 de julho de 2014 Aceito em 18 de novembro de 2014

\section{Resumo}

A declaração de novembro de 2013 do Secretário de Estado dos Estados Unidos, John Kerry, de que "a era da Doutrina Monroe terminou" é uma excelente oportunidade para rediscutir essa que é considerada um dos princípios cardeais da política externa norte-americana para a América Latina desde a independência dos Estados latino-americanos. O presente artigo pretende jogar luz em um aspecto frequentemente menosprezado pelas análises acerca da Doutrina Monroe, qual seja, o fato de que tal doutrina, longe de ser uma política concreta para todo o continente, tinha duas facetas bastante distintas tanto do ponto vista retórico como político. Através do exame principalmente de bibliografia produzida nos Estados Unidos, em especial daquelas que tiveram acesso a fontes primárias, o artigo demonstra que a Doutrina Monroe tinha um caráter claramente caribenho - e não latino-americano - a partir do reconhecimento, por parte tanto dos formuladores de política dos Estados Unidos como dos sul-americanos, de que a América do Sul era um sistema separado da América do Norte. Assim, o artigo defende que ao sul do Panamá, a Doutrina Monroe adquiriu um aspecto consideravelmente mais "multilateral", o que foi evidenciado até mesmo pelo seu famoso Corolário Roosevelt.

Palavras-chave: América do Sul; América Latina; Doutrina Monroe; política externa do Brasil; política externa dos Estados Unidos.

\section{Abstract}

The statement on November 2013 by the US Secretary of State, John Kerry, that "the Monroe era is over" is an excellent opportunity to rediscuss this, which is considered one of the guiding principles of North American foreign policy for Latin America ever since the independence of Latin American States. This paper intends to shed light on an aspect often overlooked by the analyses concerning the Monroe Doctrine, which is the fact that this doctrine, far from being a concrete policy for the whole continent, had two rather distinct traits from both the rhetorical and the political point of view. Through mainly the bibliographical review of literature produced in the US, in special that which had access to primary sources, this paper shows the Monroe Doctrine had a clearly Caribbean — and not Latin American—character, from the acknowledgement, by both US and South American policy-makers, that South America was a system apart from North America. Thus, this paper champions that to South Panama the Monroe Doctrine acquired a considerably more "multilateral" aspect, which has been shown even by its famous Roosevelt Corollary.

Keywords: South America; Latin America; Monroe Doctrine; Brazilian foreign policy; US foreign policy. 